\title{
Дискуссионный клуб
}

DOI : 10.31363/2313-7053-2019-3-36-41

\section{Гениальные идеи и гениальные ошибки \\ (Нематериальная теория психики - второе сообщение)}

\author{
Решетников М.M. \\ Восточно-Европейский Институт Психоанализа, Санкт-Петербург
}

Резюме. В развитие идей, изложенных в статье «Критическое переосмысление применения фармакотерапии при психических расстройствах», автором проводится критический анализ работ Декарта, И.М. Сеченова и М.П. Павлова, которые на столетия определили методы изучения психики и терапевтические подходы к терапии психических расстройств. Подробно анализируются: работа И.М. Сеченова «Рефлексы головного мозга», а также идеи И.П. Павлова о второй сигнальной системе и высшей нервной деятельности. Автором обосновывается, что эти идеи, которые все еще оказывают значительное влияние на развитие психологии, психиатрии, психотерапии и всех социальных наук о человеке и социуме, применительно к психической деятельности являются ошибочными.

Ключевые слова: биологический интерфейс, вторая сигнальная система, высшая нервная деятельность, мозг, нематериальная теория психики, рефлекс.

\section{Genius Ideas and Genius Mistakes \\ (Non-material Nature of the Psyche, Part II)}

Reshetnikov M.M.

East-European Psychoanalytic Institute, St. Petersburg

Summary. The author develops ideas, which he presented in his paper Critical rethinking of the use of pharmacotherapy in mental disorders and critically analyses works by Descartes, I.M. Sechenov and I.P. Pavlov, which determined our methods of studying the psyche and treating mental disorders for many centuries. Reflexes of the Brain by I.M. Sechenov and ideas of the second signal system and higher nervous activity by I.P. Pavlov are analysed in detail. The author proves that these ideas, which still influence development of psychology, psychiatry, psychotherapy and social sciences, are fallacious.

Key words: biological interface, second signal system, higher nervous activity, brain, non-material theory of the psyche, reflex.

$\mathrm{B}$ нашей предыдущей публикации в журнале «Обозрение психиатрии и медицинской психологии имени В.М. Бехтерева» [5] была сформулирована идея о мозге, как биологическом интерфейсе между идеальным и реальным, и обоснована Нематериальная теория психики. В целях самого простого объяснения этой идеи проводилась аналогия между а) мозгом и психикой, и б) компьютером (Hardware, обычно обозначаемым как «железо») и его программным обеспечением (Software), которое, сколько компьютер не разбирай, найти невозможно. Эти идеи разрабатывались в течение последних десяти лет и неоднократно представлялись научному сообществу $[6-10,14-17]$. В основу новой теории было положено одно из ключевых положений современной академической науки о том, что информация - это не материя и не энергия, а нематериальный фактор [1], который не существует вне субъекта и при отсутствии субъекта.

В предшествующих публикациях было также обосновано, что на протяжении двух тысячелетий ученые не замечали ошибочную подмену понятий: они говорили и писали об изучении и о терапии психики, а изучали и «лечили» мозг, параллельно изобретая псевдо-физиологическую терминологию для описания «мозговых механизмов психических процессов». В отличие от этих устаревших подходов, автор рассматривает психику как

информационную структуру, а психическую деятельность как вариант информационного обмена и взаимодействия, которые возникают и функционируют только в случае раннего погружения ребенка в социальную (информационную) среду, как своеобразную глобальную сеть. Однако в первой статье критический пересмотр гипотезы Гиппократа о мозге, как вместилище всех психических процессов, а также анализ развития этой гипотезы в работах Декарта [2], И.М. Сеченова [11] и И.П. Павлова [4] был дан в предельно кратком варианте. Учитывая общенаучную значимость этих вопросов, а точнее-гениальных заблуждений, предлагается рассмотреть вклад этих авторов в развитие научных представлений о психике более подробно.

Как отмечал сам Декарт, он потратил несколько месяцев, анатомируя головы разных животных, надеясь найти объяснение, в чем состоит память, внимание и прочее [2]. Естественно, это ему не удалось. Тем не менее, достижения его гения общепризнаны, и для этого есть вполне определенные основания. Это был период, когда ученые начали склоняться к материалистическим (большей частью- механистическим) объяснениям своих открытий и наблюдений. Например, Уильям Гарвей, который открыл систему кровообращения, в своем описании апеллировал к уже хорошо известным человечеству техническим устрой- 
ствам - трубам и насосам, отмечая, что по такой же (механической) схеме действует кровеносная система тела человека. Но Декарт расширяет этот принцип и переносит представления о механизмах внутренней регуляции организма на систему взаимодействия организма с внешним миром, по сути, предлагая механистическую концепцию психической деятельности.

Согласно этой концепции Декарта, взаимодействие организма с внешним миром осуществляется некой «нервной машиной», в которой мозгу (в полном соответствии с гипотезой Гиппократа) отводилась роль центра. От мозга во все части тела расходятся «нервные трубки» с «нитями», которые, натягиваясь или ослабляясь, открывают некие «клапаны», которые пропускают нервные импульсы от мозга к тем или иным частям тела (по аналогии с тем, как кровь проходит по сосудам). Повторим еще раз: в теории Декарта тело мыслится как машина, функционирующая по законам механики, а всеми его движениями управляет мозг. Тем не менее, душа в системе представлений Декарта еще присутствует и наделена собственной активностью, но этот тезис теории Декарта вспоминают не так уж часто. В качестве его главной заслуги обычно отмечается, что он фактически описал рефлекторную дугу, хотя сам термин "рефлекс» в его работах не использовался.

Прежде чем мы перейдем к эпохальной работе И.М. Сеченова «Рефлексы головного мозга» (1863), где этот термин (рефлекс) обрел полные права «гражданства» в мировой науке, обратимся к историческому периоду, когда была написана эта статья. В 1859 году вышел уникальный труд Ч. Дарвина «Происхождение видов путём естественного отбора, или Сохранение благоприятных рас в борьбе за жизнь», который стал мощным стимулом для пересмотра мировоззренческих позиций у абсолютного большинства ученых мира. Более того, постепенно распространились отчасти ложные представления, что быть ученым и не быть дарвинистом - просто невозможно или, во всяком случае - неприлично. За прошедшие 160 лет значимость этой монографии практически не изменилась, несмотря на все еще продолжающуюся полемику по поводу теории дарвинизма. Одни считают ее реальным описанием эволюции всего живого на нашей планете, а другие склонны оценивать ее, как описание генетического единства (или даже как «единства акта творения») и наиболее последовательную классификацию всех живых существ. Тем не менее, публикация этого уникального научного труда была, безусловно, революционным событием, которое значительной частью мирового научного сообщества того периода однозначно интерпретированным, как торжество материализма над идеализмом. Уже в 1861 году переводы отрывков и рецензий на книгу Ч. Дарвина публикуются в России, буквально всколыхнув весь научный мир. Более того, теория Ч. Дарвина активно обсуждается не только учеными, а всей высокообразованной российской интеллигенцией.
На этой волне редактор литературного альманаха «Современник» известный русский поэт Н.А Некрасов обращается к своему знакомому-молодому, по-европейски образованному, преподавателю Медико-хирургической академии И.М. Сеченову с предложением написать для этого журнала статью с обзором наиболее значимых проблем естествознания. В итоге появляется, скорее не статья, а трактат под названием «Попытка ввести физиологические основы в психические процессы». Однако государственная цензура и Священный Синод (в тот период-высший орган управления делами Православной церкви) запретили публикацию «опасного сочинения», которое, по официальному заключению, «оскорбляло чувства верующих». Переписка по этому поводу между редакций литературного альманаха, цензорами и Священным Синодом по объему многократно превосходит саму статью и представляет самостоятельный интерес [12]. В итоге статья выходит в «Медицинском вестнике» под сугубо научным названием «Рефлексы головного мозга» (11). Какие только определения в последующем не давали этой, безусловно, заслуживающей внимания, но глубоко ошибочной статье: «начало эры объективной психологии», «действительный инструмент анализа сложнейших механизмов работы мозга», «острое оружие научной полемики по многим актуальным проблемам современной нейрофизиологии» и т.д. И т.п. Мной умышленно опускаются авторы этих оценок, но цитировать В.И. Ленина все еще без ссылок не принято, поэтому приведу точно: «Он, этот научный психолог (И.М. Сеченов - прим. моё-М.Р.), отбросил философские теории о душе и прямо взялся за изучения материального субстрата психических явлений - нервных процессов» [3].

Нужно сказать, что статья, начинающаяся словами: «Вам, конечно, случалось, любезный читатель, присутствовать при спорах о сущности души и ее зависимости от тела», - написана чрезвычайно талантливо, но в стиле, скорее, даже не трактата, а эссе, то есть-свободной композиции личных соображений автора по конкретному поводу. Примечательно, что в самом начале статьи, после противопоставления себя всяческим дилетантам, автор констатирует, что мнение человека, который обладает некоторым авторитетом в этой сфере, легко «возводится в догму», а сам такой (компетентный) автор «легко делается кумиром». Это, собственно, и произошло в последующем и с самим произведением, и с его автором, что ничуть не умаляет историческую ценность и значимость и первого, и второго.

В целом в тексте И.М. Сеченова встречается множество бездоказательных утверждений и допущений, типа: «говорят обыкновенно...», «стало быть...», «пусть не думает читатель...», «в этом смысле...», «как бы то ни было...» и т.д. А теперь приведем ведущие постулаты автора этой работы: «Войдемте же, любезный читатель, в тот мир явлений, который родится из деятельности головного мозга. Говорят объкновенно, что этот мир охваты- 


\section{Дискуссионный клуб}

вает всю психическую жизнь, и вряд ли есть уже теперь люди, которые с большими или меньшими оговорками не принимали бы этой мысли за истину» (курсив и далее мой - М.Р.) [11, с.32]. "Для нас, как для физиологов, достаточно и того, что мозг есть орган души, т.е. такой механизм, который, будучи приведен, какими ни на есть причинами в движение, дает в окончательном результате тот ряд внешних явлений, которыми характеризуется психическая деятельность» [11, с.32]. «Читателю становится разом понятно, что все без исключения качества внешних проявлений мозговой деятельности, которые мы характеризуем, например, словами: одушевленность, страстность, насмешка, печаль, радость и пр., суть не что иное, как результат большего или меньшего укорочения какой-то группы мышц-акта, как всем известно, чисто механического» $[11$, с.33]. «Стало быть, головной мозг, орган души, при известных условиях (по понятиям школь) может производить движения роковым образом, то есть, как любая машина, точно так, как например, в стенных часах стрелки двигаются роковым образом оттого, что гири вертят часовые колеса» [11, с.37]. Остановимся на этом. И даже не будем пытаться критиковать талантливого автора (с позиций современного знания критиковать гениев прошлого всегда легко), а проведем лишь критическую переоценку самого главного, что было сделано в этой работе.

Напомним, что в представлениях Декарта душа еще рассматривалась как самостоятельная структура, обладающая собственной активностью. В отличие от этого в концепции И.М. Сеченова душевная жизнь полностью сведена к механистической по своей сути и содержанию гипотезе о внутренней деятельности головного мозга, реакциям возбуждения и торможения нервных клеток, до этого подробно изученных И.М. Сеченовым в процессе опытов с раздражением мозга лягушки кристаллами соли. Не могу не отметить, что к чести автора, в конце своей статьи И.М. Сеченов отмечает: «Наконец я должен сознаться, что строил все эти гипотезы, не будучи почти вовсе знаком с психологической литературой» [11, с.116].

Наш выдающийся соотечественник И.П. Павлов прочитал статью «Рефлексы головного мозга» еще в ранней юности, когда учился в рязанской духовной семинарии, и эта работа, по его собственному выражению, перевернула всю его жизнь. Напомним, что, отталкиваясь от представлений И.М. Сеченова, И.П. Павлов разработал теорию условных рефлексов, представления о первой и второй сигнальной системах и о высшей нервной деятельности. Никакого пересмотра теории И.М. Сеченова сделано не было, но был сделан ряд значительных шагов вперед в изучении нервной системы, о которых будет сказано чуть позднее.

А пока проанализируем: что еще происходило после исторической работы И.М. Сеченова? Перечислим максимально кратко общеизвестные факты, чтобы не утонуть в отступлениях, и обратимся только к самым выдающимся открытиям физи- ологов, главные из которых практически во всех случаях отмечались Нобелевскими Премиями.

В 1897 году Ч. Шеррингтон сформулировал представления о синапсах (пересмотрев декартовские представления о непрерывных «нервных трубках»), но Нобелевскую Премию он получил только через 40 лет - в 1932 году за достижения в изучении структуры нервной системы. В 1904 Нобелевскую Премию получил И.П. Павлов за изучение деятельности пищеварительных желез (хотя, по сути - за открытие условных рефлексов). В 1906 году Нобелевская Премия была присуждена К. Гольджи и С. Рамон-и-Кахаль за описание структуры и организации нейронов в различных областях головного мозга. В 1921 году О. Лёви установил химическую природу передачи нервного возбуждения через синапсы и роль ацетилхолина (он получил Нобелевскую Премию в 1936 году). В 1933 году А.В. Кибяков установил роль адреналина в синаптической передаче. В 1935 году В. Эрспамер открыл «энтерамин», в последующем названный серотонином, а в 1953 И. Пейдж и Б. Твэрег обнаружили серотонин в головном мозге, который оказался также нейромедиатором и получил неофициальное наименование «гормона хорошего настроения» или «гормона счастья».

Обратим внимание, что изучение нервной системь и мозга шло все более тонкими методами, но его роль, как вместилищза всех психических проиессов, никем не подвергалась сомнению. Более того, обоснованная выше «подмена понятий» и примитивная идентификация нервного и психического вообще никем не замечалась! В силу этого внимание ученых, описывающих психические и психопатологические феномены в псевдофизиологической терминологии, постепенно перемещалось от реакций возбуждения и торможения в головном мозге и представлений о высшей нервной деятельности к псевдо-биохимической интерпретации психических процессов (к «химии психики»), а точнее-к обмену нейромедиаторов в синаптической щели.

Отталкиваясь от уже упомянутого выше метафорического наименования серотонина («гормон счастья»), И.П. Лапин совместно со своим ассистентом Г.Ф. Оксенкрагом в 1969 выдвинул и опубликовал [13] очень осторожную гипотезу о том, что, возможно, развитие депрессий (в настоящее время - самой массовой психопатологии) связано с обменом (дефицитом) серотонина в синаптической щели. Эта идея сразу после публикации была подхвачена ведущими психофармакологическими фирмами. Как в конце жизни с оттенком иронии рассказывал сам И.П. Лапин (именуя себя «дедушкой Прозака»), эта чисто умозрительная гипотеза в срочном порядке была теоретически и экспериментально обоснована, и вслед за этим появилась новая, постоянно расширяющаяся группа медицинских препаратов под интригующим и красивым наименованием «селективные ингибиторы обратного захвата серотонина».

Следует отметить, что сам И.П. Лапин относился к такой реализации его идеи весьма скеп- 
тически и даже с некоторым чувством вины. Мне не раз приходилось слышать от него саркастически звучащую фразу: «Они долго искали душу, и наконец - о чудо (!), нашли ее в синаптической щели!». При этом он никогда не говорил «мы искали»- только «они».

Странно, но никто из разработчиков этой гипотезы даже не задумался, что в этом предельно оглупленном подходе к терапии депрессий есть определенный элемент цинизма и даже кощунства. Назначая препараты этой группы сроком на 6-8 месяцев, а иногда рекомендуя их пожизненное применение («по аналогии с инсулином у диабетиков»), врачи как бы молчаливо признавали и убеждали мало осведомленную и даже просвещенную публику: «Это не утрата любимого ребенка или другого близкого человека, материального или социального статуса, идеалов или смысла жизни спровоцировали депрессию-это просто следствие нарушения обмена нейромедиаторов». О том, как мои сомнения по всем этим вопросам привели меня вначале к гипотезе о «биологическом интерфейсе», а затем к Нематериальной теории психики, было подробно написано в первой публикации в «Обозрении психиатрии...» [5], а также в ряде других [6-10].

Теперь обратимся к И.П. Павлову и его идее о второй сигнальной системе, которая, по сути, явилась одной из главных предпосылок обоснованной автором Нематериальной теории психики. Напомним, что первая сигнальная система, которая реализуется на основе рефлекторной деятельности и мозговых механизмов (является общей для людей и всех животных), связывалась И.П. Павловым с подкорковыми образованиями. А вторая сигнальная система интерпретировалась как преобразование, в павловской терминологии - «сигнала сигналов» (слов, сейчас мы бы сказали-информации, прим М.Р.) в ассоциативных полях коры головного мозга, что И.П. Павлов обозначил как «высшую нервную деятельность» (ВНД).

Вначале своих исследований и обобщений И.П. Павлов стоял на строгих физиологических позициях и под страхом увольнения запрещал своим сотрудникам психологизировать его опыты по выработке условных рефлексов и даже просто употреблять такие слова как «собака догадалась», «захотела», «пожелала». Однако позднее учение об условных рефлексах было некритически перенесено на всю психику и привнесено в академическую психологию и психиатрию.

Наиболее полно эта смена позиции И.П. Павлова была обозначена в его докладе на XIV Международном физиологическом конгрессе в Риме 2 сентября 1932 года. Процитирую две выдержки из этого доклада: «Я убежден, что приближается важный этап человеческой мысли, когда физиологическое и психологическое, объективное и субъективное действительно сольются, когда фактически разрешится или отпадет естественным путем мучительное противоречие или противопоставление моего сознания моему телу» [4]. «Эту реальную и са- мыми общими линиями только что мной очерченную деятельность больших полушарий с ближайшей подкоркой, деятельность, обеспечивающую нормальные сложные отношения целого организма к внешнему миру, законно считать и называть вместо прежнего термина «психической»-высшей нервной деятельностью» [4, с.482].

Это, конечно, великая ошибка великого ученого: в рефлексе психики не больше, чем в лампочке, снабженной сенсором, который срабатывает всякий раз, когда появляется какой-то движущийся объект. Однако под влиянием авторитета И.П. Павлова и его не менее талантливых и авторитетных последователей многие ученые до настоящего времени пытаются найти материальный субстрат психики или хотя бы его электрические или волновые эквиваленты в коре головного мозга и больших полушариях. Увы, бесполезно, никакого материального субстрата психики нет - она нематериальна.

Теория И.П. Павлова, которая отражала современное ему развитие науки, оказала и, попрежнему, оказывает огромное влияние на развитие физиологии, клинической психиатрии и научной психологии. До сих пор в трудах моих уважаемых современников обнаруживаются ссылки на приведенные выше цитаты и фразы, подобные той, которую я процитирую без ссылки на авторство (но автор есть, и весьма заслуженный): «Мозг может не только адекватно отвечать на раздражители, но и предвидеть будущее, активно стоить планы поведения и реализовать их в действии». Увы, мозг-это просто ткань, и он ничего предвидеть не может!

Еще раз подчеркнем, что, независимо от этого критического пересмотра его теоретических построений, И.П. Павлов остается выдающимся ученым-физиологом и одним из гениев XX века. Что касается его вклада в клиническую медицину и психологию, о значимости которых неустанно твердили его ученики и последователи, то здесь уместно обратиться к тому, как сам И.П. Павлов оценивал проекции своей теории в смежные области знания и практики. В конце жизни он достаточно скромно констатировал: «Я не клиницист (я был и остаюсь физиологом) и, конечно, теперь - так поздно-не успею уже и не смогу сделаться клиницистом»,- и далее автор пишет, поэтому «в моих настоящих соображениях, как и в прежних моих экскурсах в невропатологию и психиатрию, я не смею при обсуждении соответствующего материала претендовать на достаточную с клинической точки зрения компетентность» $[4$, с.515]. И еще одна цитата из Полного собрания сочинений И.П. Павлова: «... Я хотел бы предупредить недоразумение в отношении ко мне. Я не отрицаю психологии как познания внутреннего мира человека» $[4$, с.104]. Надеюсь, что коллеги понимают разницу между представлениями о внутреннем мире человека и физиологией высшей нервной деятельности.

Повторим еще раз: ошибки великих ученых - это великие ошибки, и они нуждаются в са- 


\section{Дискуссионный клуб}

мостоятельном (и почтительном) изучении и анализе. Но в данном случае нельзя даже пытаться в чем-то обвинить И.П. Павлова: он гениально предчувствовал различие между нервной регуляцией соматических функций и психической деятельностью, и пытался найти объяснение последней на доступном для того периода развития науки уровне, сформулировав гипотезу о ВНД. Теория информации появилась в конце 1940-х годов, а И.П. Павлов, 170-летие с дня рождения которого весь научный мир отметит в 2019, умер в 1936. Если бы теория информации появилась раньше, возможно, И.П. Павлов сделал бы совсем иные выводы относительно второй сигнальной системы.

\section{Заключение}

Одни коллеги, ознакомившись с этим материалом, оценили нематериальную теорию психики как открытие, которое должно качественно поменять все подходы к психике и к психопатологии, и я благодарю их за такую оценку. Другие испытали реальный когнитивный диссонанс, обещая подумать (скорее, с оттенком скепсиса), так как излагаемые идеи во многом противоречили тому, чему их учили, во что они верили, на основе чего выстраивали свои научные обобщения и осуществляли свои исследовательские и терапевтические подходы и стратегии. Третьи вообще отказывались слушать и даже обсуждать эту теорию, так как «она вступает в противоречие с устоявшимися представлениями», с «признанными авторитетами» и т.д. Отчасти удивительно, но восприятие излагаемых идей в молодежной аудитории студентов и аспирантов чаще всего выражается фразой: «А что - кто-то думает иначе?». Уверен, что адекватное восприятие и понимание новой теории придет не так скоро, даже несмотря на то, что все хорошо знают: сколько радио не разбирай - музыки в нем не найдешь!

\section{Выводы:}

В предыдущей и в настоящей публикации обосновано:
1) на протяжении двух тысячелетий ученые не замечали ошибочную подмену понятий: они говорили и писали об изучении или о терапии психики, а изучали и «лечили» мозг, в том числе, с помощью лоботомии, электрошока и психофармакологии, параллельно изобретая псевдофизиологическую терминологию для описания мозговых механизмов психических процессов;

2) мозг и психика-это две тесно связанные, но принципиально разные системы;

3) мозг и нервная система-материальны и осуществляют регуляцию деятельности внутренних органов, рефлекторных реакций и адаптивных функций организма; одновременно с этим мозг является биологическим интерфейсом, осуществляющим связь между идеальным и реальным;

4) психика нематериальна - эта информационная структура, которая формируется на основе языкового программирования мозга ребенка только в социальной информационной среде, и является высшим уровнем регуляции познавательных, эмоциональных, поведенческих и идеомоторных актов, то есть - соицальной адаптации личности в иелом, реализуемой в соответствии с языковыми и культурными требованиями конкретного социума, в котором эта психика была сформирована;

5) невротические и другие психические расстройства, возникающие вследствие индивидуально значимых психических травм и «ударов судьбы» (более 50\% современной психопатологии), когда одна информация (психическая травма) нарушает деятельность другой информационной системы (психики) - не связаны с патологией мозга;

6) такие психические расстройства требуют качественно иных клинических подходов и качественно иной парадигмы терапии и реабилитации, мишенью которых является не мозг, а психика;

7) современная академическая наука фактически еще не изучала психику, как информационную (идеальную, нематериальную) структуру, что потребует пересмотра парадигмы всех наук о человеке.

\section{Литература}

\begin{tabular}{|c|c|c|}
\hline 1 & $\begin{array}{l}\text { Винер Н. Кибернетика или управление и } \\
\text { связь в животном и машине. - М.: Совет- } \\
\text { ское радио. - } 1968 .-325 \text { с. }\end{array}$ & $\begin{array}{l}\text { Wiener N. Cybernetics, or control and communication } \\
\text { in the animal and the machine). - Moskva: Sovetskoe } \\
\text { radio, 1968:325 (In Rus.). }\end{array}$ \\
\hline 2 & 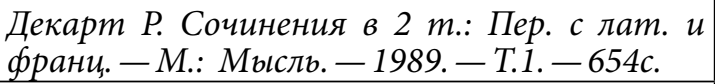 & $\begin{array}{l}\text { Descartes R. Collected works. } 2 \text { volumes. Volume } \\
\text { 1.-Moskva: Misl, 1989:654 (In Rus.). }\end{array}$ \\
\hline 3 & $\begin{array}{l}\text { Ленин В.И. Полное собрание сочинений. Изд. } \\
\text { 4-е. - Москва: Государственное издатель- } \\
\text { ство политической литературы. - 1941- } \\
\text { 1967. - Т.1. - С.127. }\end{array}$ & $\begin{array}{l}\text { Lenin V.I. Collected works. The 4th edition, Volume } \\
\text { 1. - Moskva: Gosudarstvennoe izdatelstvo politiches- } \\
\text { koy literaturi, 1941-1967:127 (In Rus.). }\end{array}$ \\
\hline 4 & $\begin{array}{lcr}\text { Павлов И.П. Полное собрание } \\
\text { дов.-М.;-Л.: } & \text { Академия } \\
\text { СССР.-1949. - } & \text { Т.ІІІ, кн.1.- С.104, 323-340, } \\
\text { 349. } & \end{array}$ & $\begin{array}{l}\text { Pavlov I.P. Collected works. Volumes 1-5. - Moskva- } \\
\text { Leningrad: Academiya nauk SSSR. - Tom III, Chast } \\
\text { 1. 1949: 104, 323-340, } 349 \text { (In Rus.). }\end{array}$ \\
\hline
\end{tabular}




\section{Дискуссионный клуб}

\begin{tabular}{|c|c|c|}
\hline 5 & $\begin{array}{l}\text { Решетников М.М. Критическое переосмыс- } \\
\text { ление применения фармакотерапии при пси- } \\
\text { хических расстройствах // Журн. Обозрение } \\
\text { психитрии и медицинской психологии име- } \\
\text { ни В.М. Бехтерева. - 2017. - №2. - С.17-21. }\end{array}$ & $\begin{array}{l}\text { Reshetnikov M.M. Critical rethinking of the use of } \\
\text { pharmacotherapy in mental disorders. Obozrenie psi- } \\
\text { hiatrii I meditsinskoi psihologii im. V.M. Bekhtereva. } \\
2017: 17-21 \text { (In Rus.). }\end{array}$ \\
\hline 6 & $\begin{array}{l}\text { Решетников М.М. Психодинамика и пси- } \\
\text { хотерапия депрессий.-СПб.: Восточно- } \\
\text { Европейский Институт Психоанали- } \\
\text { 3a.-2003. -328c. }\end{array}$ & $\begin{array}{l}\text { Reshetnikov M.M. Psychodynamics and psychothera- } \\
\text { py of depressions. St.Peterburg: Vostochno-Evropeisky } \\
\text { Institut Psikhoanaliza, } 2003 \text { : } 328 \text { (In Rus.). }\end{array}$ \\
\hline 7 & $\begin{array}{l}\text { Решетников М.М. Психическая трав- } \\
\text { ма.-СПб.: Восточно-Европейский Инсти- } \\
\text { тут Психоанализа.-2006.-322с. (2-е изд. } \\
\text {-М.: Юрайт.-2018). }\end{array}$ & $\begin{array}{l}\text { Reshetnikov M.M. Psychic trauma. St.Peterburg: } \\
\text { Vostochno-Evropeisky Institut Psikhoanaliza, 2006 : } \\
\text { 322. Second ed.-Moskva: Urait, 2018. (In Rus.). }\end{array}$ \\
\hline 8 &  & $\begin{array}{l}\text { Reshetnikov M.M. Psychic disorder. St.Peterburg: } \\
\text { Vostochno-Evropeisky Institut Psikhoanaliza, 2008 : } \\
\text { 272. Second ed.-Moskva: Urait. - 2017. (In Rus.). }\end{array}$ \\
\hline 9 & $\begin{array}{l}\text { Решетников М.М. Критический постмате- } \\
\text { риализм в психологии и психиатрии // Не- } \\
\text { врологический Бюллетень.-Bвьn. XLIII, Том } \\
\text { 2. - Казань. - 2011. - С.66-69. }\end{array}$ & $\begin{array}{l}\text { Reshetnikov M.M. Critical postmaterialism in psy- } \\
\text { chology and psychiatry. Nevrologicheskiy Buleten, Ka- } \\
\text { zan, - T. XLIII, Volume. 2. 2011:66-69 (In Rus.). }\end{array}$ \\
\hline 10 & $\begin{array}{|lll|}\text { Решетников } & \text { М.М. Идеи имеют самосто- } \\
\text { ятельную } & \text { жизнь. -Журн. } \\
\text { пия. - } 2018 .- \text {-№ } & 8 .- \text {-С.44-50. } \\
\end{array}$ & $\begin{array}{l}\text { Reshetnikob M.M. Ideas live their own life. Psikhote- } \\
\text { rapia. \# } 8 \text { (189), 2018: 44-50 (In Rus.). }\end{array}$ \\
\hline 11 & $\begin{array}{|lrr|}\text { Сеченов } & \text { И.М. Рефлексы головного моз- } \\
\text { га.-М.: } & \text { Министерство } & \text { просвешения } \\
\text { СССР. }-1953 .-117 c .(\text { С.32, } 33,36,37) . \\
\end{array}$ & $\begin{array}{l}\text { Sechenov I.M. Reflexes of the brain. - Moskva: Minis- } \\
\text { terstvo prosvyastcheniya SSSR, } 1953: 31,32,33,36 \text {, } \\
37,117 \text { (In Rus.). }\end{array}$ \\
\hline 12 & $\begin{array}{l}\text { Терехов П.Г. И.М. Сеченов и материалисти- } \\
\text { ческая психология. - Москва: Академия наук } \\
\text { СССР. - 1957. - С.55-109. }\end{array}$ & $\begin{array}{l}\text { Terekhov P.G. Sechenov I.M. and materialist psychol- } \\
\text { ogy. - Moskva: Academiya nauk SSSR. - 1957: 55- } \\
109 \text { (In Rus.). }\end{array}$ \\
\hline 13 & $\begin{array}{l}\text { Lapin I. P., Oxenkrag G. F. Intensification of } \\
\text { the central serotoninergic processes as a pos- } \\
\text { sible determinant of thymoleptic effect. - Lan- } \\
\text { cet. - 1969. - N1. - P.132-136. }\end{array}$ & $\begin{array}{l}\text { Lapin I. P., Oxenkrag G. F. Intensification of the cen- } \\
\text { tral serotoninergic processes as a possible determinant } \\
\text { of thymoleptic effect. - Lancet, 1969, N } 1 \text { p. 132-136. }\end{array}$ \\
\hline 14 & $\begin{array}{l}\text { Reshetnikov M.M. What is the Psyche? } \\
\text { What are we Curing?-Journ. Anthropolo- } \\
\text { gy.-2017. - Vol.6. - P.11-15. }\end{array}$ & $\begin{array}{l}\text { Reshetnikov M.M. What is the Psyche? What are we } \\
\text { Curing? - Journ. Anthropology. - 2017. - Vol.6. P.11- } \\
\text { 15. }\end{array}$ \\
\hline 15 & $\begin{array}{l}\text { Reshetnikov M.M. Problem of Relation between } \\
\text { Brain and Mind in Physiology, Medicine and } \\
\text { Psychology. - Journ. of Psychiatry and Psychiat- } \\
\text { ric Disorders. - 2017. - Vol.1. - P.313-316. }\end{array}$ & $\begin{array}{l}\text { Reshetnikov M.M. Problem of Relation between } \\
\text { Brain and Mind in Physiology, Medicine and Psy- } \\
\text { chology. - Journ. of Psychiatry and Psychiatric Dis- } \\
\text { orders. - 2017. - Issue1. - P.313-316. }\end{array}$ \\
\hline 16 & $\begin{array}{l}\text { Reshetnikov M.M. During Two Thousand Years } \\
\text { We Were Looking for the Psyche in a Wrong } \\
\text { Place (Ideas Live Their Own Life). - Interna- } \\
\text { tional Journal of Current Innovations in Ad- } \\
\text { vanced Research. - 2018. - Vol.1. - P.82-87. }\end{array}$ & $\begin{array}{l}\text { Reshetnikov M.M. During Two Thousand Years } \\
\text { We Were Looking for the Psyche in a Wrong } \\
\text { Place (Ideas Live Their Own Life). - International } \\
\text { Journal of Current Innovations in Advanced Re- } \\
\text { search. - 2018. - Vol.1, Issue4. - P.82-87. }\end{array}$ \\
\hline 17 & 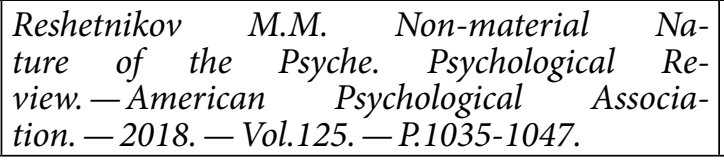 & $\begin{array}{l}\text { Reshetnikov M.M. Non-material Nature of the Psyche. } \\
\text { Psychological Review. - American Psychological Asso- } \\
\text { ciation. - 2018; 125:1035-1047. }\end{array}$ \\
\hline
\end{tabular}

Сведения об авторе

Решетников Михаил Михайлович - доктор психологических наук, кандидат медицинских наук, профессор, Заслуженный деятель науки РФ, ректор Восточно-Европейского Института Психоанали3a. E-mail: veip@yandex.ru 